today's shrinking world the World Health Organization has prepared a special issue of the Weekly Epidemiological Record $^{9}$ giving information for international travellers. It covers (a) the list of countries and areas where the risk of contracting malaria is present, even though it may be remote; (b) advice on how to protect travellers from that risk; and (c) guidance on what to do if fever develops on returning home. The document is divided into two parts. One part presents data on the risk of malaria in some 220 countries and territories all over the world. The second part gives an outline of preventive measures, including chemoprophylaxis. A succinct table of appropriate drugs and their dosages is appended together with a map showing the epidemiological assessment of the status of malaria in 1972.

This document is a useful source of the information that travel agencies, tourist information centres, and other organizations dealing with international travel ought to give their clients. It will also help doctors faced with inquiries about proposed or previous visits abroad.

1 British Medical fournal, 1971, 3, 1.

2 British Medical fournal, 1972, 2, 604.

3 Shute, P. G., and Maryon, M., British Medical fournal, 1969, 2, 781 Bruce-Chwatt, L. J., Draper, C. C., and Peters, W., British Medical Fournal, 1971, 2, 91 .

5 Dorolle, P., British Medical fournal, 1968, 4, 789.

6 World Health Organizaticn, Weekly Eoidsmiological Record, 1973, No. 1.

7 Smitskamp, H., and Wolthuis, F. H., British Medical fournal, 1971, 1. 714.

8 British Medical fournal, 1972, 3, 652.

9 World Health Organization, Information on Malaria Risk for International Travellers, reprinted from Weekly Epidemiological Record 1973, No. 3, 25. Obtainable from W.H.O., 1211 Geneva 27, Switzerland.

\section{Extensive Resections for Cancer of the Large Bowel}

Despite considerable individual exceptions, in general the malignancy of carcinomas varies greatly according to the viscus in which they arise. Thus, carcinomas of the bronchus or oesophagus carry a particularly unfavourable prognosis and are seldom amenable to eradication by surgery or irradiation with any prospect of lasting cure. Carcinoma of the stomach is usually a somewhat more favourable lesion. For example, of a large series of cases seen in the hospitals of the Birmingham area, about $5 \%$ were alive and well five years later, and the crude five-year survival rate for those patients fortunate enough to have been able to proceed to a radical operation was $15.6 \% .{ }^{1}$ Even more promising for surgical treatment, as a rule, are carcinomas of the rectum and colon. Some $50 \%$ of the patients followed up by various authors ${ }^{2-6}$ after radical operation for carcinoma of the rectum were alive and well five years afterwards, and it is usually reckoned that the survival rate for patients who have had radical surgery for carcinoma of the colon is even better. $^{4-7}$ Admittedly these figures of survival mostly represent the achievements of particularly experienced surgeons working in specialized or major centres, and the patients admitted to them may be to some extent selected. The outcome of surgery for colorectal cancer throughout the country as a whole may be rather less satisfactory..$^{89}$ But these superlative results set a standard of excellence towards which all surgeons should aspire.

Obviously if a patient is to enjoy the benefits of radical surgery for carcinoma of the bowel his growth must be considered to be resectable. Consequently it behoves the surgeon operating on such cases not to be easily deterred from excision by local fixation of the lesion, provided it is not associated with peritoneal or extensive hepatic deposits. Adherence to other viscera and to the abdominal parietes may sometimes present the surgeon with a formidable fixed mass necessitating for its removal an extensive resection of colon or rectum together with en-bloc excision of part or the whole of adjoining organs. These may be the uterus and uterine appendages, vagina, urinary bladder, seminal vesicles, prostate, loops of small intestine, kidney and ureter, stomach, duodenum, spleen or pancreas, or the musculo-aponeurotic layers of the abdominal wall may too have to be excised. Naturally the prognosis after multivisceral resections could scarcely be expected to be as good as after simple resections of non-adherent growths, but it is often much better than was expected at the time of operation. For one thing, as J. C. Goligher $^{10}$ and R. V. Cooke, ${ }^{11}$ have emphasized, though the carcinoma may have appeared to the surgeon to have extended into the adherent viscus or parietes, sometimes when the specimen is examined by the pathologist subsequently the adhesions are found to be purely inflammatory and not to contain growth. Secondly, even if malignant infiltration is present, complete eradication of the lesion may still be possible, as shown by the reports of many long-term survivors after such operations. ${ }^{11-15}$ For example, of 11 patients subjected to multiple resections by Cooke, ${ }^{11}$ six survived for over five years (four over 12 years); of 21 patients reported by J. van Prohaska and colleagues, ${ }^{12}$ all of whom had cancerous infiltration of the adjoining resected organs, nine achieved five-year survival; and of six cases recently published by Harold Ellis and colleagues ${ }^{15}$ requiring concomitant partial excision of the duodenum one has survived over six years and the two others are still living and well $3 \frac{1}{2}$ and two years respectively afterwards.

There is a further consideration the surgeon has to bear in mind when faced with very adherent colorectal growths of this kind. It is that, even when complete cure is not obtained by multiple organ resection and the patient eventually succumbs from recurrence in two or three years' time, a greater degree of palliation is usually afforded temporarily when the primary growth has thus been removed than when it has been merely bypassed or a proximal colostomy alone has been performed. ${ }^{1}$

\footnotetext{
1 Brookes, V. S., Waterhouse, J. A. H., and Powell, D. J., British Medical .7ournal, 1965, 1, 1577.

2 Dukes, C. E., Proceedings of the Roval Society of Medicine, 1957, 50, 1031 3 Bussey, H. J. R., Proceedings of the Royal Society of Medicine, 1963, 56, 494 4 Grinnell, R. S., Surgery, Gynecology and Obstetrics, 1953, 96, 31.

5 Gilbertsen, V. A., Surgery, 1959, 46, 1027.

- Cutler, S. J., and Lourie, W. I., National Cancer Institute Monograph, 1964, No. 15, p. 281.

Rankin, F. W., and Olsen, P. F., Surgery, Gynecology and Obstetrics, $1933,56,366$.

8 Slaney, G., in Modern Trends in Surgery, ed. W. T. Irvine. London, Butterworth, 1971 .

- Walker, R. M., Rebort of South Western Regional Cancer Bureau. Bristol, S.W. Regional Hospital Board, 1972.

10 Goligher, J. C., British Medical fournal, 1941, 2, 393.

11 Goligher, J. C., British Medical fournal, 1941, 2, 393. 18, 46. V., Annals of the Royal College of Surgeons of England, 1956,
. M. Van Prohaska, J., Grovostis, $M$.

18 Brunschwig, A., and Daniel, W., Annals of Surgerv, 1960, 151, 571.

14 Bricker, E. M., Butcher, H. R., jun., Lawler, W. H., jun., and McAfee, C. A., Annals of Surgery, 1960, 152, 388

15 Ellis, H., Morgan, M. N., and Wastell, C., British fournals of Surgery, $1972,59,932$.
} 